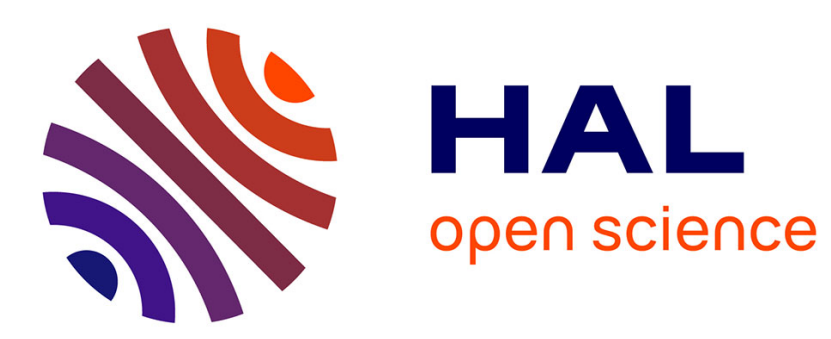

\title{
High Frequency Permeability of Mn-Zn Ferrite and its Composite Materials
}

\author{
T. Tsutaoka, T. Kasagi, T. Nakamura, K. Hatakeyama
}

\section{To cite this version:}

T. Tsutaoka, T. Kasagi, T. Nakamura, K. Hatakeyama. High Frequency Permeability of Mn-Zn Ferrite and its Composite Materials. Journal de Physique IV Proceedings, 1997, 07 (C1), pp.C1-557-C1-558. 10.1051/jp4:19971230 . jpa-00254904

\section{HAL Id: jpa-00254904 https://hal.science/jpa-00254904}

Submitted on 1 Jan 1997

HAL is a multi-disciplinary open access archive for the deposit and dissemination of scientific research documents, whether they are published or not. The documents may come from teaching and research institutions in France or abroad, or from public or private research centers.
L'archive ouverte pluridisciplinaire HAL, est destinée au dépôt et à la diffusion de documents scientifiques de niveau recherche, publiés ou non, émanant des établissements d'enseignement et de recherche français ou étrangers, des laboratoires publics ou privés. 


\title{
High Frequency Permeability of Mn-Zn Ferrite and its Composite Materials
}

\author{
T. Tsutaoka, T. Kasagi, T. Nakamura* and K. Hatakeyama** \\ Physics Laboratory, Faculty of School Education, Hiroshima University, 1-1-1, Kagamiyama, \\ Higashi-Hiroshima 739, Japan \\ * R\&D Division, Toda Kogyo Corporation, Funairi-minami, Hiroshima 730, Japan \\ ** Resources \& Environment Protection Research Laboratories, NEC Corporation, Miyazaki, \\ Miyamae-ku Kawazaki, Kanagawa 213, Japan
}

\begin{abstract}
Complex permeability spectra $\left(\mu^{*}=\mu^{\prime}-i \mu^{\prime \prime}\right)$ in Mn-Zn ferrite and its composite materials have been studied. In sintered ferrite, resonance-type frequency dispersion was observed at room temperature but decrement of $\mu$ ' is steeper than that of ordinary resonance. As the temperature is decreased, onset frequency of dispersion shifts higher and dispersion character changes to relaxation-type. In ferrite composite materials, relaxation characters were also observed at low volume loading samples. Since $\mathrm{Mn}-\mathrm{Zn}$ ferrite has relatively high electrical conductivity at room temperature, high frequency permeability is suppressed by eddy current. However, lowering of temperature and reduction of ferrite content result in the decrease of eddy current; magnetic resonance such as relaxation-type spin rotational one appears in high frequency region.
\end{abstract}

\section{INTRODUCTION}

For high-frequency electronic devices such as electromagnetic wave absorbers or inductor devices, initial permeability in high-frequency region is an important factor. So-called high-permeability ferrite has large permeability value in low frequency region, however their permeability rapidly decreases in high frequency region. We have investigated the $\mathrm{Ni}-\mathrm{Zn}$ ferrite composite materials to improve high-frequency permeability, and have shown that the ferrite composite material can have higher permeability than sintered ferrite in $100 \mathrm{MHz}$ region [1]. The permeability of polycrystalline ferrite can be described as the superposition of domain wall motion and spin rotation components; for $\mathrm{Ni}-\mathrm{Zn}$ ferrite, we can separate these two contributions in permeability spectra using the difference of frequency dependence (resonance-type for the domain wall motion and relaxation-type for the spin rotation). In the present work, we have studied high-frequency permeability spectra for $\mathrm{Mn}-\mathrm{Zn}$ ferrite composite materials and temperature variation of permeability spectra for sintered $\mathrm{Mn}$-Zn ferrite to investigate the variation of these two components with ferrite content and temperature.

\section{EXPERIMENTAL}

Sintered ferrite samples used for this work had the cationic composition of $\mathrm{Mn}_{0.51} \mathrm{Zn}_{0.44} \mathrm{Fe}_{2.05} \mathrm{O}_{4}$ which density is 4.9. $\mathrm{Mn}-\mathrm{Zn}$ ferrite particles for composite materials were prepared by mechanical grinding of the sintered ferrite. Particle size was controlled under $75 \mu \mathrm{m}$. MnZn ferrite - PPS composite materials were produced by mixing the ferrite particles with appropriate amount of PPS (Polyphenylene Sulfide) resin, pressing the mixture at $300^{\circ} \mathrm{C}$ and a pressure of $120 \mathrm{kgf} / \mathrm{cm}^{2}$ then cooling to room temperature. The complex permeability $\left(\mu^{*}=\mu^{\prime}-\mathrm{i} \mu^{\prime \prime}\right)$ was measured from $10 \mathrm{kHz}$ to $3 \mathrm{GHz}$ by a coaxial line technique using an impedance analyzer and a network analyzer in the temperature range from $80 \mathrm{~K}$ to $400 \mathrm{~K}[1]$.

\section{RESULTS AND DISCUSSION}

Figure 1 shows the complex permeability spectra of a sintered

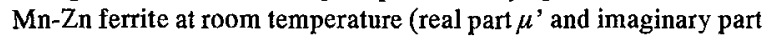
$\left.\mu^{\prime \prime}\right)$. The real part $\mu^{\prime}$ starts to decrease at about $100 \mathrm{kHz}$, falls off

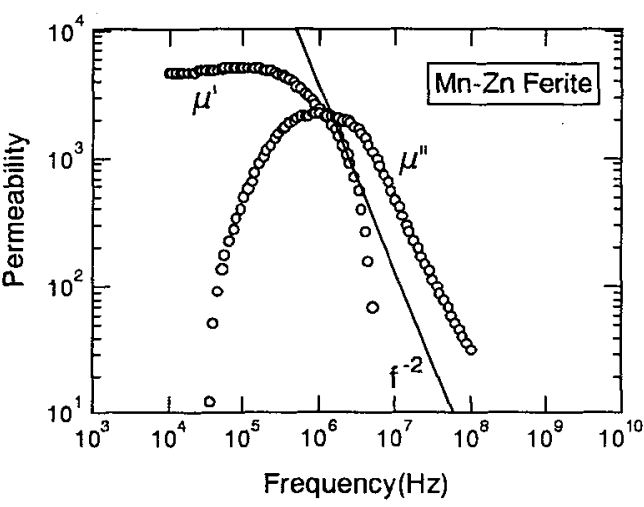

Figure1: Permeability spectra of a sintered $\mathrm{Mn}-\mathrm{Zn}$ ferrite. Solid line shows $\mathrm{f}^{-2}$ line (f:frequency). 


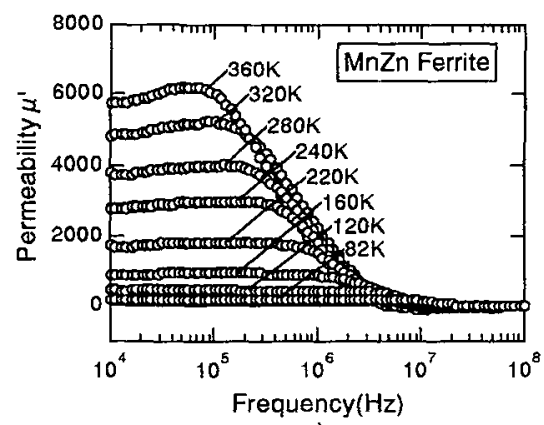

a)

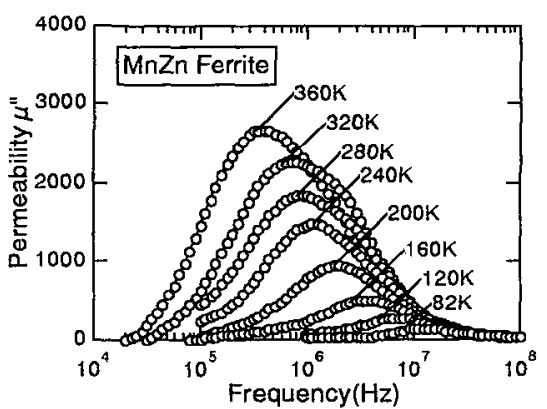

b)

Figure2: Temperature variation of complex permeability spectra for sintered ferrite. Real part a) and imaginary part b).

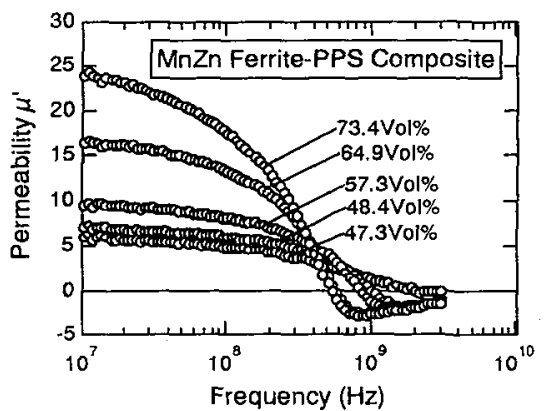

a)

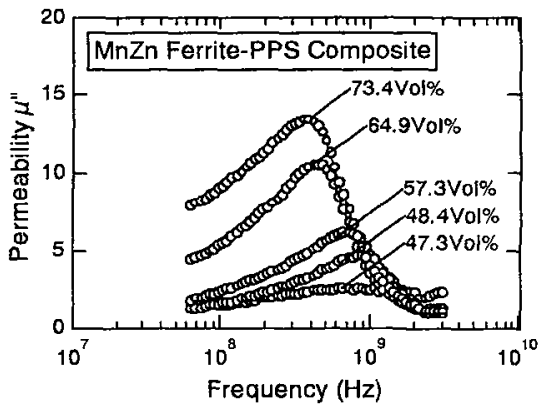

b)

Figure3: Real a) and imaginary b) part of permeability $\mu^{\prime}$ and $\mu^{\prime \prime}$ for $\mathrm{Mn}-\mathrm{Zn}$ ferrite composite materials.

rapidly from about $3 \mathrm{MHz}$. The imaginary part $\mu^{\prime \prime}$ has a maximum at around $800 \mathrm{kHz}$. This is a resonance-type of dispersion but decrement of $\mu^{\prime}$ is steeper than that of ordinary dispersion due to domain wall resonance[2,3]. Figure 2 shows the variation of the real a) and imaginary part b) of permeability spectra with temperature for sintered $\mathrm{Mn}$ - Zn ferrite. It was found that the $\mu$ ' decreases and shoulder frequency of $\mu$ ' increases with a decrease of temperature. Further, dispersion character changes from resonance-ty pe to relaxation-type as the temperature is decreased; broad maximum of $\mu$ ' disappears in low temperature region. Maximum frequency of $\mu$ " shifts higher and $\mu$ " value decreases with a decrease of temperature. This feature can be understood as follows. Since $\mathrm{Mn}-\mathrm{Zn}$ ferrite is a semiconductor, a contribution of eddy current for high-frequency permeability is large at room temperature[4]. Accordingly, permeability dispersion due to magnetic resonances are masked, especially high-frequency spin resonance is invisible in permeability spectra. As temperature is decreased, conductivity decreases and magnetic anisotropy increases. Therefore, resonance frequency shifts higher, simultaneously, relaxation-type spin rotational resonance appears in permeability spectra.

For $\mathrm{Mn}-\mathrm{Zn}$ ferrite composite materials, the same feature was observed in low ferrite content samples. Figure 3 shows the complex permeability spectra of $\mathrm{MnZn}$ ferrite - PPS composite materials at room temperature (a) real part $\mu^{\prime}$ and b) imaginary part $\mu$ "]. Even for high ferrite content composites ( $73.4 \mathrm{vol} \%$ ), resonance frequency locates at several hundred $\mathrm{MHz}$ and permeability value at low frequency decreases drastically. However, permeability value at high frequency is larger than that of sintered ferrite. For the 47.3 vol\% composite, we can find the relaxation-type frequency dispersion. In the case of ferrite composite materials, electric properties of embedded particles are considered to be almost the same as that of bulk ferrite in this particle size. However, both magnetic and electric contacts between each adjacent particles are broken because ferrite particles are separated by nonmagnetic and insulating layer (PPS resin). This configuration results in the reduction of net conductivity in composite materials. Therefore, relaxation type spin resonance appears in high frequency permeability. From above results, high-frequency permeability can be improved by making composite structure of $\mathrm{Mn}$ - $\mathrm{Zn}$ ferrite and host resin. Further investigations for magnetic and electrical properties of sintered ferrite and composite materials are being carried out.

\section{References}

[1] T. Tsutaoka. M. Ueshima. T. Tokunaga. T. Nakamura and H. Hatakeyama., J. Appl. Phys. Vol.78, No36 (1995) $3983-3991$.

[2] A. Globus. and M. Guyot., IEEE Trans. Mag. Vol. Mag-6, No.3 (1970) 614-617.

[3] R. Lebourgeois., P. Perriat. and M. Labeyrie., "High and low level frequency losses in NiZn and MnZn spinel ferrites", ICF6 Tokyo an Kyoto Sept.29-Oct.2, T. Yamaguchi and M. Abe. (The Japan Society of Powder and Powder Metallurgy, 1992) pp.1159-1164.

[4] T. Nakano., N. Sato. and T. Nomura. J. Magn. Soc. Jpn. Vol.20 (1996) 501-504. (in Japanese) 